\title{
Synthesis
}

\section{Setting Biodiversity Targets in Participatory Regional Planning: Introducing Ecoprofiles}

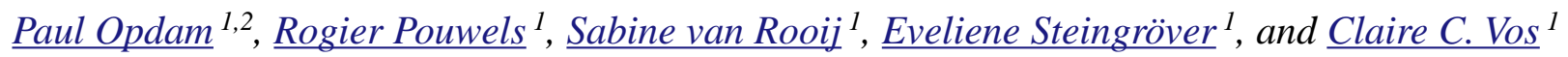

\begin{abstract}
In highly developed regions, ecosystems are often severely fragmented, whereas the conservation of biodiversity is highly rated. Regional and local actor groups are often involved in the regional planning, but when making decisions they make insufficient use of scientific knowledge of the ecological system that is being changed. The ecological basis of regional landscape change would be improved if knowledge-based systems tailored to the cyclic process of planning and negotiation and to the expertise of planners, designers and local interest groups were available. If regional development is to be sustainable, goals for biodiversity must be set in relation to the actual and demanded patterns of ecosystems. We infer a set of prerequisites for the effective use of biodiversity goal-setting methods in multi-stakeholder decision making. Among these prerequisites are the requirements that ecosystem patterns are set central and that methods integrate the demands of a suite of species, are spatially explicit, and allow the aspiration level to be modified during the planning process. The decision making must also be enriched with local ecological knowledge. The current methods for setting biodiversity targets lack crucial characteristicsin particular, flexibility - and often require too high a level of ecological expertise. The ecoprofile method we designed combines an ecosystem base with spatial conditions for species metapopulations. We report experiences with this approach in two case studies, showing that the method was understood by policy makers, planners, and stakeholders, and was useful in negotiation processes. We recommend experimenting with applying this approach in a variety of circumstances, to further improve its ecological basis.
\end{abstract}

Key Words: Biodiversity targets; ecosystem networks; landscape ecology; metapopulation persistence; multifunctional landscapes; multi-stakeholder decision making; regional planning; sustainable development

\section{INTRODUCTION}

Over an ever-increasing part of the earth, landscape changes are mainly being driven by the demands of metropolitan societies (Antrop 2006). Decision making on future land use is shifting from state-led planning toward systems of governance planning (Friedmann 1993, Haughton and Counsell 2004). At the regional level, actor groups are expected to implement biodiversity conservation goals promulgated by national and international governments, in combination with regional goals (White 2000, Brody et al. 2004, Azerrad and Nilon 2006). People living in urban and peri-urban areas rate the preservation of biodiversity highly (Brody 2003a, Brody et al. 2004). Yet although regional planning groups may know the species and habitats in their region, their ability to transfer this specific knowledge into spatially explicit ecological conditions, based on generic ecological knowledge, is limited. Concise goals, translated into specific and effective measures, are often lacking; if present, they rarely extend beyond regional planning boundaries (Prendergast et al. 1999, Brody 2003b, Termorshuizen et al. 2007). And because planners and landscape managers see scientific tools as prescribed planning decisions rather than as flexible frameworks that will guide them through a regionspecific decision process, they are reluctant to use them (Prendergast et al. 1999, Pullin et al. 2004, Azerrad and Nilon 2006). This suggests that existing methods are too complex and too rigid. Little documented research exists on how to make conservation planning models operational for planning processes that build on stakeholder involvement (Knight et al. 2006).

\footnotetext{
${ }^{1}$ Alterra Landscape Centre, Wageningen University and Research, ${ }^{2}$ Department of Land Use Planning, Wageningen University
} 
In this paper, we address the problem of reducing the complexity of ecological tools for incorporating biodiversity in regional landscape planning while maintaining the flexibility required in the planning and design process. We approach this problem from the planner's perspective, taking into account how decisions are made in landscape planning. Basically, we propose that sustainable landscape planning for biodiversity requires (1) setting a clear biodiversity goal and (2) designing a landscape pattern that provides the appropriate ecological conditions. These two steps in decision making are like the water level in communicating vessels (Fig. 1), illustrating the principle that form follows function. In this paper, we focus on the first step, but have to take the second step into account.

Participatory planning is a complex multi-layered negotiation process with parallel rather than sequential steps and feedback loops (Healy 1996, Lenz and Peters 2006). Hence, the two steps identified in the previous paragraph are part of a complex and cyclic negotiation. Throughout this negotiation, stakeholders with an interest in nature conservation attempt to maximize biodiversity levels, but pressure from other land claims will force them to adjust the planned ecological conditions. The initially preferred biodiversity goal may turn out to be unachievable further on in the process: for example, because a key site is claimed for other land-use purposes. Thus, goals and conditions are shifted up and down between preferred and minimum acceptable levels, but need to be kept functionally balanced (Fig. 1).

In the first (strategic) phase of planning, in which goals are set, many uncertainties have to be considered and the details of the final landscape plan are still out of sight. Consequently, a method for goal setting needs to be quite general and flexible, but at the same time spatially explicit. This paper presents a design for a method for setting biodiversity goals that meets these requirements, and explores whether and how it works in complex decision making. We discuss existing methods of biodiversity goal setting against this background, propose an improved approach, and in two applications, explore its potential value in decision making. Finally, we consider how the approach could be developed and made more rigorous.

\section{REQUIREMENTS FOR SETTING BIODIVERSITY GOALS IN REGIONAL PLANNING}

Public decision makers are abandoning the traditional species-by-species approach to conservation and instead are embracing landscape-scale approaches based on ecosystem management (Brody 2003c). However, targets in many conservation programs, such as the European Habitat Directive, are still expressed in terms of species (European Commission 1992). Therefore, any nature conservation goal setting in multifunctional regional planning needs to integrate the species approach into a spatially explicit ecosystem-based approach. The basis for this integration is the functional relationship between population performance and the pattern of ecosystem patches. The key characteristics of ecosystem patterns determining the sustainable future of populations are the ecosystem type and the abiotic qualities, coverage, and spatial cohesion of ecosystem patches (Hobbs 2005, Opdam et al. 2003, Wiegand et al. 2005, Gaston et al. 2006). Because these conditions manifest at a range of spatial scales (Vos et al. 2001, Cumming et al. 2006), the effectiveness of biodiversity-inclusive regional planning depends on the ability of planning groups to account for ecosystem patterns extending beyond the boundary of their planning area.

The participation and engagement of the public may enhance the quality of ecosystem management plans. The criteria of plan quality include specified goals and objectives, the consideration of transboundary ecological interactions, and clearly defined actions that safeguard natural resources (Brody 2003c, Termorshuizen et al. 2007). The involvement of land owners and managers, citizens, and pressure groups is important during all steps of the planning process: not only at the start (scoping) and at the end (evaluation) (Bentrup 2001), but also during the spatial analysis of the ecosystem pattern (Johnson and Campbell 1999) and the goal-setting and design phases. As stakeholders participating in planning processes will not support what they do not understand (Theobald et al. 2000), decision support tools for choosing common and measurable goals need to be understandable to the lay person. The effectiveness of conservation management is thought to be closely linked to adaptive management processes that empower stakeholders, rather than to "ever-more precise techniques for prioritising elements of nature" (Knight et al. 2006). 
Fig. 1. Communicating vessels as a metaphor for the functional link between the aspiration level of biodiversity goal setting, and the required physical conditions in the landscape. The vertical arrows represent the context of the planning process, in which actors with opposing interests negotiate the desired level of biodiversity (considering national biodiversity policy goals) and the allocation and spatial combination of land-use functions.

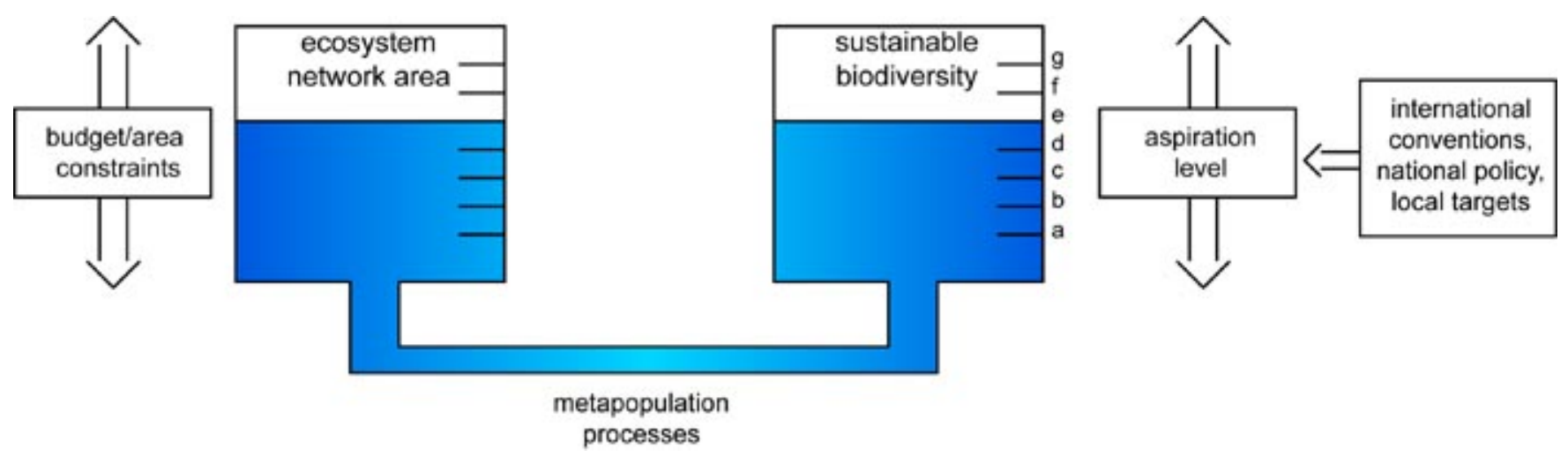

Therefore, we need simple goal-setting methods that allow aspiration levels to be modified during the planning process.

The well-known species-area curve highlights the principle that the greater the number of species for which viable populations are demanded in an area, the larger the ecosystem area has to be. Metapopulation ecology studies have elucidated the key roles of ecosystem patch size and ecosystem network size (Hanski et al. 1996, Verboom et al. 2001). As land in metropolitan regions is expensive and in short supply, the feasible level of sustainable species diversity depends primarily on sufficient area of good-quality ecosystem. Furthermore, the spatial distribution of that area is a key factor in determining the number of species in sustainable populations (Day and Possingham 1995, Wahlberg et al. 1996, Hanski 1999, Opdam et al. 2003). Thus, the goal-setting techniques used in such negotiations should be related to the total amount and to the spatial configuration of ecosystem types that are considered significant from a conservation point of view.

Because comprehensive and reliable data on species distributions and on population and ecosystem performance are often lacking for specific planning regions, there is an urgent need to combine local expertise with more general technical knowledge
(Balram et al. 2004). Thus, goal-setting methods should allow for the incorporation of local expertise. Another consequence is that we often have to work with biodiversity surrogates based on conditions for potential occurrence rather than on observations of actual occurrence. Such surrogates (as indicators of biodiversity richness levels) are more likely to be successful if they are negotiated and constructed in the science-policy interface of specific problems and settings (Turnhout et al. 2007).

Based on this overview, we propose the following requirements for a goal-setting method: (1) The use of the goal-setting method should not require expertise on complex ecological processes or statistical procedures, nor repeated model runs during the planning process. (2) The method should allow planning with ecosystems based on species requirements. (3) The method needs to be spatially explicit, based on: ecosystem type, quality, area, and spatial configuration. (4) The method should allow stakeholders to modify the goal(s) during the planning process, in relation to attainable conditions. (5) The method should be applicable in metropolitan landscapes, and therefore, encompass a wide range of types of nature, not just wild land and top carnivores. (6) The approach needs to be adaptable to different spatial scales, i.e., it should allow up- and downscaling, e.g., by organizing species in a hierarchical or nested system 
(Fleishman et al. 2002). (7) The method should also be adaptable to the regional setting and capable of being enriched with local ecological knowledge. In the next section, we use these criteria to assess the suitability of existing biodiversity goal-setting methods.

\section{CURRENT APPROACHES}

Most current approaches for target setting using surrogates for biodiversity are built on single species, e.g., flagship, keystone, or umbrella species (Simberloff 1998, Caro and O'Doherty 1999, Roberge and Angelstam 2004). These indicators have primarily been used for determining the minimum size for large conservation areas or for selecting sites to include in protected area programs (Carignan and Villard 2002). As we have argued above, single-species approaches are inappropriate in a multifunctional planning context (Table 1). The single-species approach does not allow shifts between aspiration levels for biodiversity and is not sensitive to changes of area and configuration of small ecosystem patches at the regional level (Andelman and Fagan 2000). Another criticism is that single species do not represent the whole range of species of an ecosystem (Chase et al. 2000, Poiani et al. 2001).

Landscape planning asks for multi-species approaches. The focal species approach (Lambeck 1997) is a systematic procedure for the selection of a suite of umbrella species. Per ecosystem type, all species considered to be at risk are grouped according to the key impact factor, including composition of the ecosystem, quantity and configuration of ecosystem area and management regimes (Freudenberger and Brooker 2004). PadoaSchioppa et al. (2006) have claimed that the approach is applicable at a range of spatial scales. However, there are some drawbacks when applying this approach in a multifunctional planning context. First, the focal species are selected on their ability to represent the needs of other species. Per ecosystem type, only the most vulnerable species are selected. When the focal species approach has been applied, well-known species groups such as birds have been used; this has raised doubts about the indicator value of the surrogate for responses by other vertebrates (Lindenmayer and Fisher 2003, Lindenmayer et al. 2002). Furthermore, because the method produces a single conservation goal, it is impossible to shift between aspiration levels during the negotiation process. Also, the method is data greedy, and if applied in governance processes, requires great ecological expertise. Beazley and Cardinal (2004) liberalize the systematic species selection, and involve a team of regional experts in the selection of focal species, using a Delphi survey matrix approach based on species vulnerability in human-modified landscapes. They conclude that the approach reduces ambiguity and subjectivity in species selection while using local expert knowledge, which is a valuable insight for spatial planning. Yet their approach results in a single planning design and does not allow shifts in aspiration levels during the planning process. Sanderson et al. (2002) extend the focal species approach toward the landscape scale, introducing the "landscape species concept." A set of landscape species uses large, ecologically diverse areas, relies on the composition and configuration of the landscape, and often has a significant impact on structure and function. Coppolillo et al. (2004) emphasize the suitability of the landscape species method for large, relatively undisturbed areas. However, this method is less suitable for metropolitan landscapes, as conditions for species with large ranges cannot be realized.

Other approaches are being developed in practice and can be found on the internet, e.g., the conservation action planning (CAP) website of The Nature Conservancy (http://conserveonline.org/wo rkspaces/cbdgateway/cap/practices/). Their section on target setting promotes three basic types of conservation target setting: ecological systems, ecological communities, and species in five categories. The CAP is primarily developed for management and land-use plans for large continuous tracts of protected land and focuses on prioritizing ecosystem and community types. The species layer is considered as a fine filter in case some species are not captured well enough by the coarse filter of communities. This seems logical in cases where the prime discussion is on management issues. The CAP approach identifies threats originating in the surrounding land, but is not developed for multipurpose land-use decision making and is not suitable for negotiations on the amount of ecosystem area and its configuration.

Much has been published on various types of optimization procedures for selecting sets of reserves or protected areas based on representation of species (overview in van Teeffelen et al. 2006). Most of these approaches require species 
Table 1. Performance of biodiversity goal-setting methods on seven conditions (in columns) for effective use in multifunctional landscape planning.

\begin{tabular}{|c|c|c|c|c|c|c|c|}
\hline & 1 & 2 & 3 & 4 & 5 & 6 & 7 \\
\hline & $\begin{array}{c}\text { Low-level } \\
\text { ecological } \\
\text { expertise } \\
\text { suffices }\end{array}$ & $\begin{array}{l}\text { Ecosystem } \\
\text { based, with } \\
\text { species re- } \\
\text { quirements }\end{array}$ & $\begin{array}{l}\text { Suitable for } \\
\text { regions with } \\
\text { fragmented } \\
\text { ecosystems }\end{array}$ & $\begin{array}{l}\text { Shifts bet- } \\
\text { ween aspi- } \\
\text { ration levels } \\
\text { for biodiv- } \\
\text { ersity }\end{array}$ & $\begin{array}{l}\text { Application } \\
\text { in multifu- } \\
\text { nctional la- } \\
\text { ndscapes } \\
\text { possible }\end{array}$ & $\begin{array}{c}\text { Up- and } \\
\text { downscaling } \\
\text { easy }\end{array}$ & $\begin{array}{l}\text { Adaptable in } \\
\text { local setting }\end{array}$ \\
\hline $\begin{array}{l}\text { Single-species approaches. } \\
\text { Flagship, keystone, umbrella }\end{array}$ & + & $\diamond$ & $\Delta$ & $\Delta$ & $\Delta$ & $\Delta$ & $\diamond$ \\
\hline $\begin{array}{l}\text { Focal species approach, } \\
\text { systematically selected }\end{array}$ & $\diamond$ & + & + & $\diamond$ & + & + & $\diamond$ \\
\hline $\begin{array}{l}\text { Focal species selected by regional } \\
\text { experts }\end{array}$ & $\diamond$ & + & + & $\diamond$ & + & $\diamond$ & + \\
\hline Landscape species approach & $\diamond$ & + & - & $\diamond$ & $\diamond$ & $\diamond$ & + \\
\hline $\begin{array}{l}\text { Multispecies reserve selection } \\
\text { optimizations }\end{array}$ & - & + & - & - & + & + & + \\
\hline $\begin{array}{l}\text { Conservation action planning } \\
\text { (CAP) }\end{array}$ & - & + & - & - & - & - & + \\
\hline
\end{tabular}

distribution data and use complicated statistics and modeling techniques. Recently published techniques incorporate extinction probabilities, in which reserves are selected on the basis of minimizing the extinction risk for multiple species (e.g., Nicholson and Possingham 2006). Cabeza and Moilanen (2001) pointed out that the impact of computational site-selection tools in applied conservation planning has been minimal. Because current optimization techniques require great professional expertise, we consider them inappropriate for stakeholder-led planning processes.

In our view, none of the approaches reviewed above meets the condition of flexibility in negotiation processes (Table 1), and most are too complicated. We conclude that the focal species approach based on local expert knowledge offers the best prospects, but needs to be made less dependent on ecological expertise and availability of regional data and more adaptive in the planning process, and should be better incorporated into an ecosystem-based approach. In the next section, we propose an approach based on this idea.

\section{PROPOSING THE ECOPROFILE MATRIX}

The ecoprofile approach builds on the broadly accepted insight (e.g., Bani et al. 2002, Opdam et al. 2003, Melbourne et al. 2004, Watson et al. 2005, Wiegand et al. 2005) that, at the landscape level, the distribution of species is determined by ecosystem type, quality, area, and connectivity. Vos et al. (2001) suggested that average patch carrying capacity and ecologically scaled average patch distance were good predictors of the proportion of patches in networks occupied by a species. They proposed the term "ecoprofile" for groups of species with rather similar positions along these two axes of spatial variation. Here, we define an ecoprofile in the context of networks rather than network 
patches: a set of species demanding similar dimensions of ecosystem network in order to persist at a regional scale. "Similar" is meant here in a relative sense, and refers to the similarity in choice of ecosystem type, area requirements, and dispersal capacity of the species encompassed by a single ecoprofile, relative to the differences between species classified in other ecoprofiles.

Together, ecoprofiles fill the theoretical space encompassed by the spatial variation of network size and network configuration. We can visualize this by arranging a suite of ecoprofiles in a multidimensional matrix (Fig. 2). The first dimension is the ecosystem type because, in planning, ecosystem types are often treated separately. The ecosystem type contains the habitat (s) of a variety of species. Although these species may differ in habitat demands at the micro level, at the landscape planning level they can often be regarded as inhabiting the same ecosystem type. For our purpose, we will neglect the variation in habitat quality within an ecosystem patch, and just assume that, if there is enough area, the habitat of any species living in the ecosystem type can be found there. The second dimension defines the ecosystem area requirements for each ecoprofile and corresponds to the carrying capacity of the ecosystem network. This axis can be scaled with a variety of measures of the area requirements of species, e.g., minimum key patch area (Verboom et al. 2001), or the minimum habitat network area (Opdam et al. 2003). These indicators, expressed as carrying capacity, can also incorporate variation in habitat quality. For example, low ecosystem quality can be compensated for by enlarging the minimum required area (Verboom and Pouwels 2004, van der Grift and Pouwels 2006).

The third dimension encapsulates ecoprofilespecific requirements related to the configuration of ecosystems. This axis can be scaled by various measures related to connectivity, e.g., maximum distance between the patches of an ecosystem, based on the dispersal distance encompassed by an ecoprofile. Also, a distinction can be made between barrier-sensitive ecoprofiles, including those for ground-dwelling species, and ecoprofiles that are not barrier sensitive.

The matrix is an open structure that can be adapted to the regional setting, as local experts can link target species in conservation programs to the cells of the matrix. Thus, by classifying the diversity of species into a nested set of ecoprofiles, based on generalized ecological traits of species, we obtain a set of surrogates for biodiversity levels directly linked to the most important spatial characteristics per ecosystem type: total area and its configuration across the planning area. It shows how the number of ecoprofiles with sustainable conditions in the region increases with total area, enabling stakeholders to negotiate a feasible aspiration level for biodiversity. In the next two sections, we will illustrate the application of the ecoprofile matrix in two planning settings.

\section{PLANNING ROBUST CORRIDORS}

In the 1990s, the Dutch government launched the National Ecological Network (NEN; Ministry of Agriculture, Nature and Fisheries (MANFS) 1990). Conceived as a structure of existing nature areas that was to be made more robust and cohesive by enlarging areas, improving environmental quality, and developing new areas and local ecological corridors, the NEN was an answer to habitat loss and fragmentation - the prime causes of the loss of biodiversity in the Netherlands (Lammers and Zadelhoff 1996). The biodiversity objectives of the NEN were defined in terms of target ecosystems and target species (Bal et al. 2001). In 2000, halfway through the implementation process, the predicted outcome of the implementation process was compared with the environmental and spatial conditions required for an effective protection of the targeted assets. It was concluded that the expected spatial cohesion would still be insufficient, because the protected areas were too small and insufficiently connected. The implementation of the planned ecological corridors was too slow (Beentjes and Koopmans 2000) and 50\% was predicted to be ineffective due to design shortcomings (Bal and Reijnen 1997).

As a solution, a planning and design process in which both scientists and policy makers participated resulted in a proposal to extend the current design of the NEN with "robust corridors" (Pelk et al. 2000). This proposal was adopted by the national government and by the 12 provinces that were to implement the policy (MANFS 2001). In this process, we used an ecoprofile matrix to facilitate the planning of the corridors by the national government and the provinces. The variety in target ecosystem types was reduced to 11 categories: e.g., forest on sandy soils, forest on clay soils, dry heath, 
Fig. 2. Design of three-dimensional ecoprofile matrices, one per identified ecosystem type, based on the carrying capacity of regional ecosystems (vertical axis), and the inter-patch distance that can be crossed during dispersal. Species are assigned to cells in the matrix by their habitat preference, individual habitat area requirements, and dispersal capacity. Each cell in the matrices represents one ecological profile.

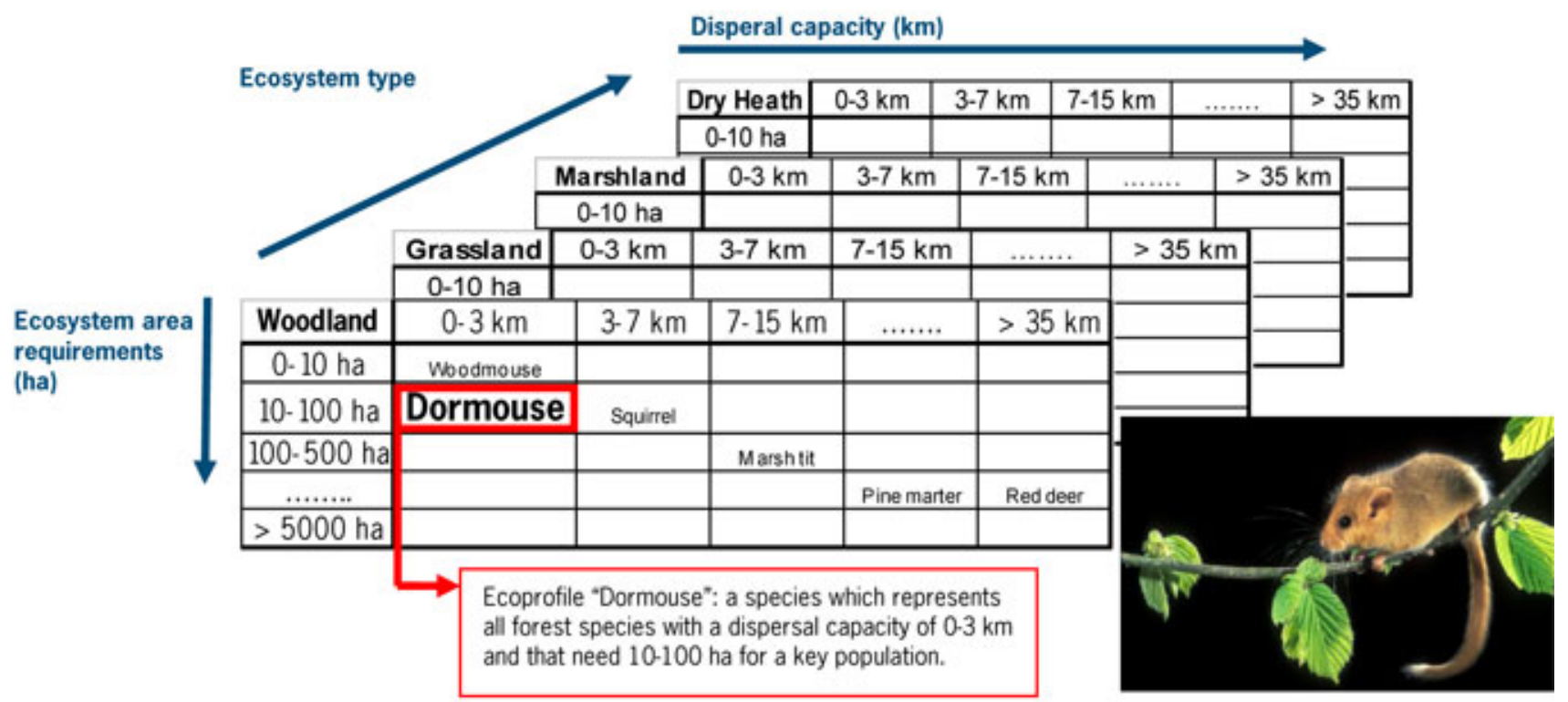

and marshland. The 398 target species selected in the NEN were assigned to the cells of the ecoprofile matrix (Broekmeyer and Steingröver 2001) based on the ecosystem type providing them with habitat, on maximum dispersal distance while crossing between ecosystem patches, and on minimum individual area requirements (Fig. 3). Thus, every ecosystem category had a set of ecoprofiles similar in spatial characteristics. Note that when assigning target species for the marshland ecosystem, not all combinations of dispersal distance and area requirements are represented (Fig. 3).

To obtain flexibility in the negotiation process between the representatives of national and provincial governments, we used variation in dispersal distance to distinguish three aspiration levels for conservation goals. At the lowest level, robust corridors are created only for species that require ecosystem networks at the national level, e. g., otter (Lutra lutra) or bittern (Botaurus stellaris). These species are relatively mobile, and effective corridors for them require the least investment. At the second aspiration level, requirements for species that form ecosystem networks at a regional level are included, e.g., grass snake (Natrix natrix) and bluethroat (Luscinia svecica). Because the dispersal capacities connected with these ecoprofiles are moderate, this goal would require wider corridors, and therefore, more investment. At the third aspiration level, the robust corridor was intended to function for all ecoprofiles, encompassing most, if not all, species inhabiting the ecosystems of the NEN. Thus, from the first to the third aspiration levels, the number of ecoprofiles for which the corridor is expected to be effective increases concomitantly with the investment required (Fig. 3 ). The method was made available to planners in 
Fig. 3. Ecoprofile matrix for ecosystem type "marshland" as applied in the Robust Corridor study. All 398 target species of the Dutch Nature Conservation Policy were assigned to the cells of the matrices for seven ecosystem types. Only 15 cells were used (as indicated by gray shading). Aspiration levels are indicated by the arrows, showing different combinations of ecoprofiles.

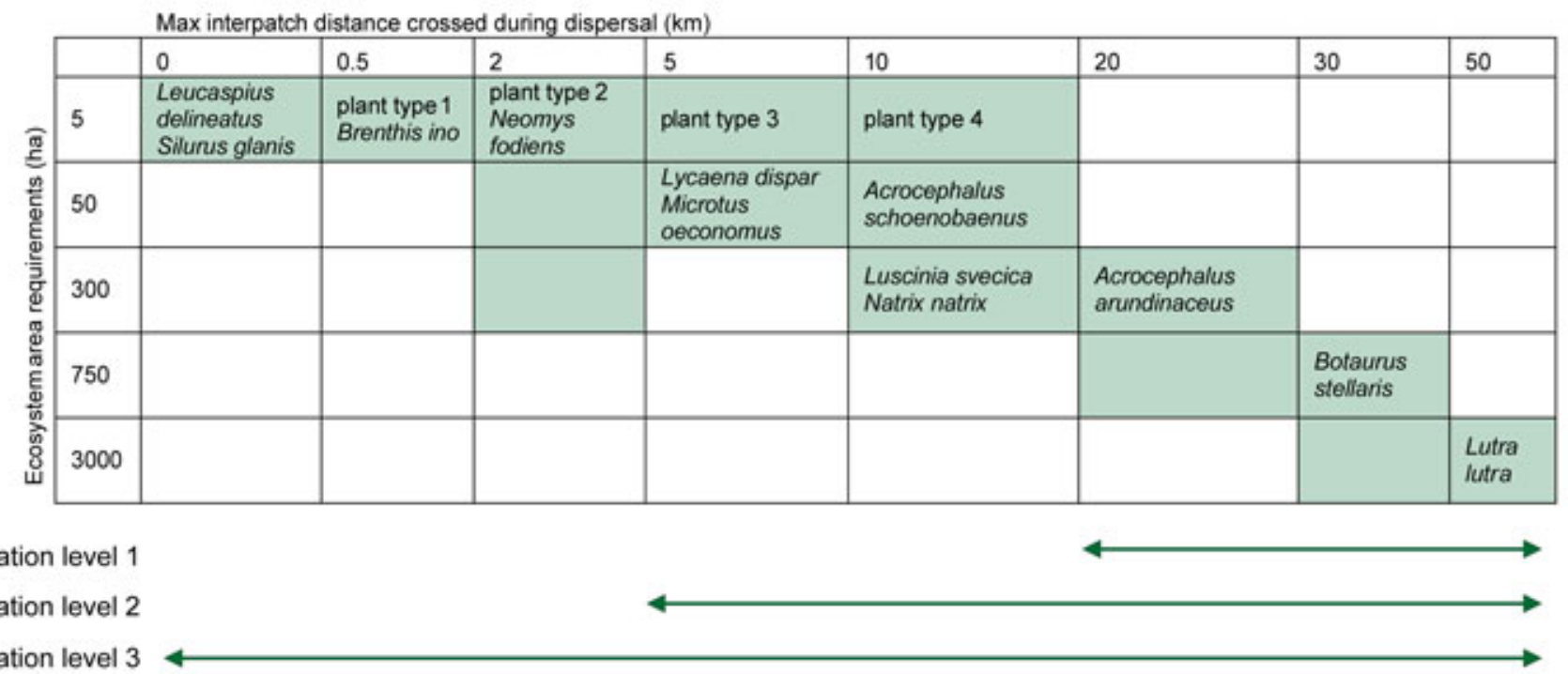

a handbook with CD-ROM (Broekmeyer and Steingröver 2001), allowing design scenarios to be generated by varying the aspiration level or the number of ecosystem types that were incorporated in the robust corridor. The designed method integrates species and focal ecosystem types and builds on two spatial dimensions of ecosystem networks (area and configuration). Its application does not require detailed knowledge of ecological processes.

In this project, we used the ecoprofile system to transfer basic ecological knowledge of individuals and populations of almost 400 species into general spatial conditions for corridor design, thus linking single-species ecology to an ecosystem design method (Vos et al. 2007). In the planning process, this method facilitated the setting of common goals by the 12 provinces and gave them flexibility in finding the preferred location. Instead of negotiating about the budget, the focus was on the required total area and designs in relation to the three alternative aspiration levels. This facilitated the complex negotiation process with the national government, during which the actors had to switch back and forth between national and provincial scales, and it stimulated a common vision for the planning of robust corridors in the Netherlands.

\section{AN ECOLOGICAL NETWORK FOR CHESHIRE, UK}

Cheshire County Council in the UK asked us to support the design process of an ecological network for the county of Cheshire, to provide a long-term planning framework for setting nature conservation priorities and selecting building blocks for an ecologically cohesive network. The planning required an open and flexible process, due to the many uncertainties (the amount of money to be invested by the County Council and various landuse stakeholders, the public support for this ecosystem network and the development of other land-use claims).

Five ecosystem types were selected by the stakeholders, which included representatives of 
nature and landscape organizations, farmers and foresters, land owners, water board managers, and county spatial planners (van Rooij et al. 2003, van der Sluis et al. 2003). For each ecosystem type, ecoprofile matrices were filled with species with known spatial characteristics, selected by the stakeholders (Fig. 4). The landscape was analyzed to quantify the area of patches of selected ecosystem types, the distances between these patches, and the location of infrastructure potentially obstructing dispersal between these patches. This resulted in maps of current ecosystem networks, each specified by an ecoprofile and for a specific ecosystem type. Each ecoprofile represents the minimum network area required for the persistence of the given species. Where differences were found between the required and actual area of these networks, the stakeholders determined whether it was feasible to upgrade the network conditions to the required level in the foreseeable future (considering developments in Cheshire and the adjacent counties). If feasible, such ecoprofiles were considered to be planning targets (Fig. 4). For the remaining ecoprofiles, it was decided that upgrading to sustainable levels was too demanding (i.e., considered unrealistic by stakeholders: Fig. 4). Thus, we used the ecoprofile approach to link species to ecosystems in a simplified, spatially explicit method for analysis and decision making on priorities. The ecological content of the approach was easily understood by the regional policy makers and stakeholders involved. They were able to upscale the regional level of biodiversity target setting with which they were familiar to a supra-regional scale, and accept that complication as a logical consequence of the principles of metapopulation ecology.

Cheshire County Council planning officers opted for two aspiration levels: a low aspiration level based on their estimation of the resources that would be available in the short term, and a higher aspiration level that would require more effort to allocate necessary resources, and could be used in a longterm perspective. This provided them with a bandwidth for negotiation in the planning process. It turned out that for two ecosystem types it would be easy to achieve biodiversity aspiration level under the low aspiration scenario, providing that resources were used for specified measures and in indicated areas. The biodiversity aspiration levels for the other three ecosystem types could only be met by the high aspiration scenario. The stakeholders readily realized that the final design could be used not only to support the choice of the lower aspiration level, but also to argue that extra resources be released for the higher aspiration levels. Thus, the approach enhanced the negotiation process. The design allowed spatial planners to shift between county level and local level, and to plan and refine several parts of the ecological network in more detail, without losing sight of the big picture. As there were no national UK targets at that time, the decisions made in Cheshire did not consider the national planning level.

\section{DISCUSSION}

\section{Discussion}

We have considered biodiversity as part of the decision making concerning the future of intensively used multifunctional landscapes, in which (semi)natural ecosystems have become fragmented and interspersed with tracts of other land use, and where land use is spatially dynamic through time. As biodiversity objectives compete for space with other land-use types, decisions concerning feasible biodiversity targets have to be done in a multipurpose setting during a complex negotiation process. Having concluded that existing methods for setting biodiversity goals were not suitable in such a planning context, we designed a new approach consisting of seven conditions inferred from collaborative multi-actor landscape planning. We tested its merits in two cases of largescale planning of ecological structures in regions encompassing both intensive agricultural and periurban landscapes. The effectiveness of the application may be illustrated by the progress made in the two planning processes. The county of Cheshire is currently implementing the strategic ecosystem network design they developed by applying the concepts of ecoprofiles and ecosystem networks (as described in van Rooij et al. (2003), see website http://www.cheshire.gov.uk/SREP/). I$\mathrm{n}$ the Netherlands, the robust corridor concept withstands considerable political discussions. It became part of the Dutch spatial planning policy framework in 2006 and is now being implemented by the provinces in cooperation with the Dutch national government (Nassauer and Opdam 2008). Also, the planning and design method developed for these corridors, which is based on the ecoprofile concept, is now being applied by consultancy bureaus for designing wildlife corridors in local planning. 
Fig. 4. An example of the use of woodland ecoprofiles sensitive to dispersal barriers (Cheshire Ecological network planning, van Rooij et al. (2003)). The species indicated were selected by the local stakeholder group. On the green background: ecoprofiles with a very sustainable habitat network covering most suitable areas in the study area; on the yellow background: ecoprofiles with potential for sustainable habitat networks in parts of suitable areas in the study area; on the red background: ecoprofiles with no potential for a sustainable habitat network in the study area; and inside the black frame: the selected target ecoprofile.

\begin{tabular}{|c|c|c|c|c|c|c|}
\hline & \multicolumn{6}{|c|}{ Dispersal capacity $(\mathrm{km})$} \\
\hline $\begin{array}{c}\text { Area } \\
\text { requirements } \\
\text { (ha) }\end{array}$ & $0-3$ & $3-7$ & $7-15$ & $15-25$ & $25-35$ & $>35$ \\
\hline $0-10$ & $\begin{array}{c}\text { European harvest } \\
\text { Mouse } \\
\text { European Water } \\
\text { shrew }\end{array}$ & & & & & $\begin{array}{l}\text { (least vulnerable } \\
\text { for } \\
\text { fragmentation) }\end{array}$ \\
\hline $10-100$ & $\begin{array}{l}\text { Dormouse } \\
\text { Slow worm }\end{array}$ & Squirrel & & & & \\
\hline $100-500$ & & & & Beaver & & \\
\hline $500-1000$ & & & & & & \\
\hline $1000-5000$ & & & & & Pine marten & Red deer \\
\hline$>5000$ & $\begin{array}{l}\text { (Most vulnerable for } \\
\text { fragmentation) }\end{array}$ & & & & & \\
\hline
\end{tabular}

Is the ecoprofile approach an ecosystem-based or a species-based approach? Application requires that target ecosystem types are chosen; subsequently, the required amount of ecosystem network area is determined. This second step is guided by the ecoprofile matrix, which serves as a means to negotiate a feasible level of the "biodiversity function" in the area, using an aspiration level set beforehand as a reference in the negotiation process. Thus, the ecoprofile is a means in negotiation. At the same time, it is assumed to have predictive power, because the concept implies that if the conditions for an ecoprofile are being realized, the species represented by the profile will be able to persist in the region. Therefore, the ecoprofile matrix serves as an intermediary between the ecosystem pattern of a region and the conditions for specific sets of species. The robust corridor case demonstrated how the method was used in negotiations between provinces and between a province and the state government about which aspiration level best matched the regional views on nature conservation, given the opportunities and constraints set by other land-use functions. The Cheshire case taught us that the ecoprofile approach can be adapted to the regional species pool. For local experts, it provides a conceptual and theoretically based structure that makes their knowledge of the region available and understandable to planners. We concluded that the method helped them focus and structure their knowledge, and link it to a flexible spatial structure for design (e.g., ecosystem networks; Opdam et al. (2006)). We suggest that this is essential for obtaining the support of local stakeholders; it also helps reduce the tension between the need for a generic method (which contributes to transparency and repeatability) and the application in a specific planning context (Caro 
and O'Doherty 1999). Cheshire stakeholders also felt that using the approach strengthened the position of biodiversity lobbyists in negotiations, because it encouraged stakeholders to cooperate and to achieve specific amounts of ecosystem area.

We believe that to ensure quality planning, decisions must be transparent and evidence based. The setting of biodiversity goals should be justified by using methods that have been replicated, tested, evaluated, and improved in the scientific domain. The ecological knowledge basis for the ecoprofile framework is still far from adequate: for many species, good data on spatial traits are not available. One way of improving the method's ecological basis is to test its predictive value on species distribution patterns in a habitat network analysis (Verboom and Pouwels 2004). Furthermore, programs for monitoring landscape changes are required, to gather data on the effectiveness of planning that has been based on the ecoprofile approach. A major challenge will be to better define the axes of the matrix and elucidate critical thresholds for the persistence of the species populations in an ecoprofile. For example, a critical threshold could be either the mean or the maximum of the variation encompassed by an ecoprofile. It is also unknown how the distribution of species over ecoprofile classes might affect these thresholds. Sensitivity analysis may help elucidate optimal class distributions, but does not provide answers to the optimal number of classes in relation to the process of decision making.

Our conclusion is that the ecoprofile matrix is an effective instrument for setting biodiversity targets in negotiations between stakeholder groups on future land use in regions with intensive land use and a high degree of fragmentation of natural ecosystems. It was readily understood by nonspecialists, and seemed to improve communication and interaction between various actors during the strategic phase of regional planning. The tool has been designed for application in the target-setting phase, and needs to be complemented with methods for design and evaluation. As the matrix lacks species-specific details on habitat requirements, it is not intended for species-oriented conservation planning. Clearly, future refinement of the approach will entail testing in a variety of landscapes and at a variety of scales, and in different planning complexities.

\section{Speculation}

Evidently, the ecological science base for our method needs further improvement. By designing this approach, we started from the viewpoint of planners, and made a number of major simplifications with unknown consequences for the adequacy of approximating biodiversity policy goals. However, it remains unclear how exact and at what level of detail biodiversity predictions must be to be good enough for complex real-world planning. We suggest that learning about necessary improvements of the ecology base should take place during a common learning process involving both planners and ecologists. The question is not so much about the level of ecological detail required to satisfy the ecologist's view, but rather about how much detail is required to allow "adequate" decision making in a variety of planning complexities and during different phases of the planning process. For example, we argue that, in the strategic stage of planning, species-specific habitat conditions are less important and would even be too detailed to incorporate in decision making. In the strategic phase, the acquisition of ecosystem area will be most critical, most difficult, and most expensive, whereas in the later engineering and management phases, setting the abiotic conditions and site management to achieve the required ecosystem quality will be most important, but will need different science support. A related issue is the trade-off between the loss of scientific credibility and ecological reliability caused by reducing the level of detail of the ecological information, and the gain in saliency and legitimacy with regard to stakeholder applications (Cash et al. 2003). For example, the method is flexible with respect to the number of ecoprofiles distinguished in the matrix, but the optimal number in relation to the application is unknown. More classes mean a better approximation of ecological complexity and improve scientific credibility, but will also increase the complexity of the decision process, with potential loss of the power to support finding solutions.

In applying ecoprofiles, we struggled with the tension between ecological realism suggested by working with "species" representing ecoprofiles, as opposed to the rough approximations of carrying capacity and dispersal distance categories. We assumed beforehand that working with "virtual" categories of species would solve the problem of inadequate knowledge of species ecology and would also reduce the complexity in handling too 
many species, but it appeared that stakeholders attributed imaginary value to "real" species and preferred to communicate in terms of "real" species. However, in doing so, they lost track of the meaning of the ecoprofile. This problem might be solved by developing a better presentation of the method, and also by showing how positions in the ecoprofile matrix represent levels of biodiversity for real regions.

In this paper, we focus on inclusion of biodiversity in land-use planning of peri-urban and agricultural landscapes with a high degree of fragmentation, high intensity of land use, and high value attributed to biodiversity. In such areas, restoration of ecosystem sites and networks is a primary conservation activity. The legitimacy of our method is based on the demands emerging from this type of biodiversity planning in a multipurpose world. One likely implication of this focus is that the applicability of the method is restricted to circumstances where the focus on ecosystem networks with discrete habitat patches embedded in an intensively used landscape matrix are an appropriate spatial conservation strategy. For example, the method assumes that these discrete ecosystem units are a good enough approximation of valuable habitat. It is also assumed that reclaimed, restored, and improved ecosystem sites will be (re) colonized by species that previously had been lost from the site or even the region. The credibility of the method will be improved if such events could be shown by monitoring.

The application of the method does not require detailed species knowledge, but does require spatial information on the distribution of ecosystem units and of properties of the landscape matrix relevant for dispersal between sites. We have not gained experience with applying our approach in circumstances where the patch-matrix model of the landscape is not a good approximation of valued nature, but we presume that, at a certain point along the landscape disturbance gradient, other methods (not considered in this paper due to unsuitability) will become more appropriate. There is a need to compare different methods across a range of fragmentation in the context of stakeholder-led decision making.
Responses to this article can be read online at:

http://www.ecologyandsociety.org/voll3/iss 1/art20/responses/

\section{Acknowledgments:}

The development of the ecoprofile approach greatly benefited from its application in the Cheshire ecological network planning commissioned by Cheshire County Council (http://www.cheshire.gov. $u k / S R E P /)$ funded by the Life-Environment Programme of the European Commission as part of the Life ECOnet Project (1999-2003). The robust corridor study was commissioned by the Dutch Ministry of Agriculture, Nature Conservation and Food Quality. The writing of this paper was financially supported by the Habiforum Research Programme Innovative Land Use.

\section{LITERATURE CITED}

Andelman, S. J., and W. F. Fagan. 2000. Umbrellas and flagships: efficient conservation surrogates or expensive mistakes? Proceedings of the National Academy of Sciences 97:5954-5959.

Antrop, M. 2006 Sustainable landscapes: contradiction, fiction or utopia? Landscape and Urban Planning 75:187-197.

Azerrad, J. M., and C. H. Nilon. 2006. An evaluation of agency conservation guidelines to better address planning efforts by local government. Landscape and Urban Planning 77:255-262.

Bal, D., H. M. Beije, M. Fellinger, R. Haveman, A. J. F. M. van Opstal, and F. J. van Zadelhoff. 2001. Handbook of nature target types. MANFS Expertise Centre report number 2001/020, Ministry of Agriculture, Nature and Fisheries, Ede, The Netherlands. (In Dutch.)

Bal, B., and R. Reijnen. 1997. Nature policy practice: efforts, effects, expectations and changes. Ministry of Agriculture, Nature and Fisheries, Ede, The Netherlands. (In Dutch.)

Balram, S., S. Dragicevic, and T. Meredith. 2004. A collaborative GIS method for integrating local and technical knowledge in establishing biodiversity conservation priorities. Biodiversity and Conservation 
13:1195-1208.

Bani, L., M. Baietto, L. Bottoni, and R. Massa. 2002. The use of focal species in designing a habitat network for a lowland area of Lombardy, Italy. Conservation Biology 16:826-831.

Beentjes, R. A., and J. C. M. Koopman. 2000. Pulsing veins: giving an impulse to the realistion of ecological corridors in the Netherlands. Projectgroup ecological corridors, internal report, Ministry of Agriculture, Nature Conservation and Fisheries, The Hague, The Netherlands. (In Dutch.)

Beazley, K., and N. Cardinal. 2004. A systematic approach for selecting focal species for conservation in the forests of Nova Scotia and Maine. Environmental Conservation 31:91-101.

Bentrup, G. 2001. Evaluation of a collaborative model: a case study analysis of watershed planning in the Intermountain West. Environmental Management 27:739-748.

Brody, S. D. 2003a. Examining the effects of biodiversity on the ability of local plans to manage ecological systems. Journal of Environmental Planning and Management 46:817-837.

Brody, S. D. 2003b. Implementing the principles of ecosystem management through local land use planning. Population and Environment 24:511-540.

Brody, S. D. 2003c. Measuring the effects of stakeholder participation on the quality of local plans based on the principles of collaborative ecosystem management. Journal of Planning Education and Research 22:407-419.

Brody, S. D., W. Highfield, and V. Carrasco. 2004. Measuring the collective planning capabilities of local jurisdictions to manage ecological systems in southern Florida. Landscape and Urban Planning 69:33-50.

Broekmeyer, M., and E. G. Steingröver, editors. 2001. Handbook of robust corridors and ecological prerequisites. Alterra Green World Research, Wageningen, The Netherlands. (In Dutch.)

Cabeza, M., and A. Moilanen. 2001. Design of reserve networks and the persistence of biodiversity. Trends in Ecology and Evolution 16:242-248.
Carignan, V., and M. Villard. 2002. Selecting indicator species to monitor ecological integrity: a review. Environmental Monitoring and Assessment 78:45-61.

Caro, T. M., and G. O'Doherty. 1999. On the use of surrogate species in conservation biology. Conservation Biology 13:805-814.

Cash, D. W., W. C. Clark, F. Alcock, N. M. Dickson, N. Eckley, D. H. Guston, J. Jäger, and R. B. Mitchell. 2003. Knowledge systems for sustainable development. Proceedings of the National Academy of Science 100:8086-8091.

Chase, M. K., W. B. Kristian, III, A. J. Lynam, M. V. Price, and J. T. Rotenberry. 2000. Single species as indicators of species richness and composition in California coastal sage scrub birds and small mammals. Conservation Biology 14:474487.

Coppolillo, P., H. Gomez, F. Maisels, and R. Wallace. 2004. Selection criteria for suites of landscape species as a basis for site-based conservation. Biological Conservation 115:419430.

Cumming, G. S., D. H. M. Cumming, and C. L. Redman. 2006. Scale mismatches in socialecological systems: causes, consequences, and solutions. Ecology and Society 11: 14 [online] URL: http://www.ecologyandsociety.org/vol11/iss1/art14/

Day, J. R., and H. P. Possingham. 1995. A stochastic metapopulation model with variability in patch size and position. Theoretical Population Biology 48:333-360.

European Commission, 1992. Council Directive 92/43/EEC of 21 May 1992 on the conservation of natural habitats and of wild fauna and flora. European Union, Brussels. (online) URL: http://ec. europa.eu/environment/nature/.

Fleishman, E., C. J. Betrus, R. B. Blair, R. MacNally, and D. D. Murphy. 2002. Nestedness analysis and conservation planning: the importance of place, environment, and life history across taxonomic groups. Oecologia 133:78-89.

Friedmann, J. 1993. Toward a non-Euclidian mode of planning. Journal of the American Planning 
Association 59:482-485.

Freudenberger, D., and L. Brooker. 2004. Development of the focal species approach for biodiversity conservation in the temperate agricultural zones of Australia. Biodiversity and Conservation 13:253-274.

Gaston, K. J., K. Charman, S. F. Jackson, P. R. Armsworth, A. Bonn, R. A. Briers, C. S. Q. Callaghan, R. Catchpole, R. Hopkins, W. E. Kunin, J. Latham, P. Opdam, R. Stoneman, D. A. Stroud, and R. Tratt. 2006. The ecological effectiveness of protected areas: the United Kingdom. Biological Conservation 32:76-87.

Hanski, I. 1999. Habitat connectivity, habitat continuity, and metapopulations in dynamic landscapes. Oikos 87:209-219.

Hanski, I., A. Moilanen, and M. Gyllenberg. 1996. Minimum viable metapopulation size. American Naturalist 147:527-541.

Haughton, G., and D. Counsell. 2004. Regions, spatial strategies and sustainable development. Routledge, New York, New York, USA.

Healy, P. 1996. The communicative turn in planning theory and its implications for spatial strategy formation. Environment and Planning B: Planning and Design 23:217-234

Hobbs, R. J. 2005. Landscapes, ecology and wildlife management in highly modified environments - an Australian perspective. Wildlife Research 32:389-398.

Johnson, B. R., and R. Campbell. 1999. Ecology and participation in landscape-based planning within the Pacific Northwest. Policy Studies Journal 27:502-529.

Knight, A. T., R. M. Cowling, and B. M. Campbell. 2006. An operational model for implementing conservation action. Conservation Biology 20:408-419.

Lambeck, R. J. 1997. Focal species: a multi-species umbrella for nature conservation. Conservation Biology 11:849-856

Lammers, G. W., and F. J. Zadelhoff. 1996. The Dutch national ecological network. Pages 101-113 in P. Nowicki, G. Bennett, D. Middleton, S. Rientjes, and R. Wolters, editors. Perspectives on ecological networks. ECNC Publications Series on Man and Nature, Volume 1. European Centre for Nature Conservation, Tilburg, The Netherlands.

Lenz, R., and D. Peters. 2006. From data to decisions. Steps in the application-oriented landscape research. Ecological Indicators 6:250 263.

Lindenmayer, D. B., and J. Fischer. 2003. Sound science or social hook-a response to Brooker's application of the focal species approach. Landscape and Urban Planning 62(3):149-158.

Lindenmayer, D. B., A. D. Manning, P. L. Smith, H. P. Possingham, J. Fischer, I. Oliver, and M. A. McCarthy. 2002. The focal-species approach and landscape restoration: a critique. Conservation Biology 16:338-345.

Ministry of Agriculture, Nature and Fisheries (MANFS). 1990. Nature policy plan 1990. MANFS, The Hague, The Netherlands. (online) URL: http://www.mnp.nl/mnc/i-en-1298.html.

- 2001. Nature policy plan 2001: nature for people, people for nature. MANFS, The Hague, The Netherlands. (online) URL: http://www.minlnv.nl/p ortal/page? pageid $=116,1640408 \& \mathrm{dad}=$ portal\& schema=PORTAL).

Melbourne, B. A., K. F. Davies, C. R. Margules, D. B. Lindenmayer, D. A. Saunders, C. Wissel, and K. Henle. 2004. Species survival in fragmented landscapes: where to go from here? Biodiversity and Conservation 13:275-284.

Nassauer, J., and P. Opdam. 2008. Design in science: extending the landscape ecology paradigm. Landscape Ecology 23: in press.

Nicholson, E., and H. Possingham. 2006. Objectives for multiple-species conservation planning. Conservation Biology 20:871-881.

Opdam, P., E. Steingröver, and S. van Rooij. 2006. Ecological networks: a spatial concept for multi-actor planning of sustainable landscapes. Landscape and Urban Planning 75:322-332.

Opdam, P., J. Verboom, and R. Pouwels. 2003. Landscape cohesion: an index for the conservation 
potential of landscapes for biodiversity. Landscape Ecology 18:113-126.

Padoa-Schioppa, E., M. Baietto, R. Massa, and L. Bottoni. 2006. Bird communities as bioindicators: the focal species concept in agricultural landscapes. Ecological Indicators 6:83-93.

Pelk, M. L. H., R. van Etteger, D. Bal, and E. Wieman. 2000. Quality by connectivity: why, where and how. Ministry of Agriculture, Nature and Fisheries, The Hague, The Netherlands. (In Dutch.)

Poiani, K. A., M. D. Merrill, and K. A. Chapman. 2001. Identifying conservation-priority areas in a fragmented Minnesota landscape based on the umbrella species concept and section of large patches of natural vegetation. Conservation Biology 15:513-522.

Prendergast, J. R., R. M. Quinn, and J. H. Lawton. 1999. The gaps between theory and practice in selecting nature reserves. Conservation Biology 13:484-492.

Pullin, A. S., T. M. Knight, D. A. Stone, and K. Charman. 2004. Do conservation managers use scientific evidence to support their decisionmaking? Biological Conservation 119:245-252.

Roberge, J. M., and P. Angelstam. 2004. Usefulness of the umbrella species concept as a conservation tool. Conservation Biology 18:76-85.

Sanderson, E. W., K. H. Redford, A. Vedder, P. B. Coppolillo, and S. E. Ward. 2002. A conceptual model for conservation planning based on landscape species requirements. Landscape and Urban Planning 58:41-56.

Simberloff, D. 1998. Flagships, umbrellas, and keystones: is single-species management passé in the landscape era? Biological Conservation 83:247-257.

Termorshuizen, J., P. Opdam, and A. van den Brink. 2007. Incorporating ecological sustainability in landscape planning. Landscape and Urban Planning 79:374-384.

Theobald, D.M., N. T. Hobbs, T. Bearly, J. A. Zack, T. Shenk, and W. E. Riebsame. 2000. Incorporating biological information in local land- use decision making: designing a system for conservation planning. Landscape Ecology 15:3545.

Turnhout, E., M. Hisschemöller, and $H$. Eijsackers. 2007. Ecological indicators: between the two fires of science and policy. Ecological Indicators 7:215-228.

van der Grift, E. A., and R. Pouwels. 2006. Restoring habitat connectivity across transport corridors: identifying high-priority locations for defragmentation with the use of an expert-based model. Pages 205-231 in J. Davenport and J. L. Davenport, editors. The ecology of transportation: managing mobility for the environment. Springer, Dordrecht, The Netherlands.

van der Sluis, T., R. G. H. Bunce, H. Kuipers, and J. Dirksen. 2003. Networks for life. Ecological network analysis for Cheshire County $(U K)$. Alterra report no. 698, Alterra Green world research, Wageningen, The Netherlands. (online) URL: http: //www.cheshire.gov.uk/SREP/.

van Rooij, S. A. M., E. G. Steingröver, and P. F. M. Opdam. 2003. Networks for life. Scenario development of an ecological network in Cheshire County. Alterra report no. 699, Alterra Green world research, Wageningen, The Netherlands. (online) URL: http://www.cheshire.gov.uk/SREP/.

van Teeffelen, A. J. A., M. Cabeza, and A. Moilanen. 2006. Connectivity, probabilities and persistence: comparing reserve selection strategies. Biodiversity and Conservation 15:899-919.

Verboom, J., R. Foppen, P. Chardon, P. Opdam, and P. Luttikhuizen. 2001. Introducing the key patch approach for habitat networks with persistent populations: an example for marshland birds. Biological Conservation 100:89-101.

Verboom, J., and R. Pouwels. 2004. Ecological functioning of ecological networks: a species perspective. Pages 65-72 in R. H. G. Jongman and G. Pungetti, editors. Ecological networks and greenways: concept, design, implementation. Cambridge University Press, Cambridge, UK.

Vos, C. C., J. Verboom, P. F. M. Opdam, and C. J. F. ter Braak. 2001. Towards ecologically scaled landscape indices. American Naturalist 157:24-51. 
Vos, C. C., P. Opdam, E. Steingröver, and R. Reijnen. 2007. Transferring ecological knowledge to landscape planning: a design method for robust corridors. Pages 227-245 in J. Wu and R. Hobbs, editors. Key topics in landscape ecology. Studies in Landscape Ecology, Cambridge University Press, New York, New York, USA.

Wahlberg, N., A. Moilanen, and I. Hanski. 1996.

Predicting the occurrence of endangered species in fragmented landscapes. Science 273:1536-1538.

Watson, J. E. M., R. J. Whittaker, and D. Freudenberger. 2005. Bird community responses to habitat fragmentation: how consistent are they across landscapes? Journal of Biogeography 32:1353-1370.

Wiegand, T., E. Revilla, and K. A. Moloney. 2005. Effects of habitat loss and fragmentation on population dynamics. Conservation Biology 19:108-121.

White, G. F. 2000. Water science and technology: some lessons from the $20^{\text {th }}$ century. Environment 42:30-38. 